\title{
Second Life en la enseñanza del Francés lengua extranjera en la universidad
}

\author{
Paloma GARRIDO ÍÑIGO \\ Universidad Rey Juan Carlos \\ Departamento de Lenguas modernas \\ paloma.garrido@urjc.es
}

Recibido: 30/10/2011

Aceptado: 06/02/2012

\section{Resumen}

El uso de Second Life como herramienta didáctica en la enseñanza de lenguas extranjeras ha experimentado un gran auge en los últimos años. La proyección del estudiante en el mundo virtual bajo la forma de un avatar ofrece innumerables ventajas en el aprendizaje lingüístico, que no queda exento sin embargo de algunos inconvenientes. En este artículo examinaremos brevemente los pros y contras de esta plataforma virtual, ejemplificando con su uso en la clase de FLE.

Palabras clave: Second Life, mundos virtuales, aprendizaje de lenguas, aprendizaje colaborativo, FLE.

\section{Second Life dans l'enseignement du Français langue étrangère à l'université}

\section{Résumé}

L'utilisation de Second Life comme outil didactique dans l'enseignement de langues étrangères connaît un grand succès depuis quelques années. La projection de l'étudiant sous forme d'un avatar dans le monde virtuel offre de nombreux avantages dans l'apprentissage langagier qui n'est cependant pas exempt de plusieurs inconvénients. Dans cet article, nous examinerons brièvement les pour et les contre de cette plateforme virtuelle et nous illustrerons son emploi dans la classe de FLE.

Mots clés: Second Life, mondes virtuels, apprentissage de langues, apprentissage collaboratif, FLE.

\section{Second Life for the Teaching of French as a Foreign Language in Academic Contexts}

\begin{abstract}
In recent years, the use of Second Life as a didactic tool in foreign language teaching has rapidly gained importance. The student's self-projection into the virtual world as an avatar offers countless benefits in language learning, though some drawbacks can also be observed. In the present paper the pros and cons of this virtual platform will be briefly analyzed, with examples illustrating its application in the FFL classroom.
\end{abstract}

Key words: Second Life, virtual worlds, language learning, collaborative learning, FFL. 


\section{Referencia normalizada}

Garrido Íñigo, P., (2012) "Second Life en la enseñanza del Francés lengua extranjera en la universidad". Thélème, Vol. 27, 161-174.

El metaverso de Second Life (SL, a partir de ahora) aparece en $2002^{1}$ de la mano de Philip Rosedeale (Linden Labs). Es un mundo sintético, creado por los usuarios, al que se accede a través de Internet. La característica que llama más la atención es que el usuario está representado por un avatar que actúa en primera persona, en un entorno que simula el mundo real, pero en el que la imaginación también es palpable a través de construcciones futuristas, ausencia de ley de la gravedad, posibilidad de volar, etc. Y lo que es más importante: si el mundo evoluciona es porque los usuarios interactúan con él; Linden Labs provee la plataforma, pero todo lo que sucede en el mundo virtual depende del usuario.

No debemos confundir este mundo virtual con un juego de rol. Second Life ${ }^{2}$, como mundo virtual, es un simulador de socialización, de interactuación entre avatares, en el que el usuario busca fundamentalmente recrear sus experiencias del mundo real, físico, pero en un envoltorio que puede ir alterando a su antojo. Es el entorno perfecto para pasar horas delante del ordenador y sentirse totalmente fascinado por esta nueva adicción en la que los bytes son sustituidos por prims $^{3}$ y en la que la moneda oficial es el linden. Y no es extraño entonces que en 2006 las empresas vieran el potencial que ofrecía SL y decidieran tener una representación en este mundo virtual. Primero, las compañías más conocidas: Coca-Cola, Adidas, IBM,... y después, las entidades culturales: la Universidad de Harvard, el Instituto Cervantes, asociaciones de investigadores y científicos de todas las áreas,...

Actualmente, SL cuenta con unos ocho millones de usuarios, aunque en línea y dependiendo del huso horario, suele haber una media de 30.000 avatares. En España hay unos 300.000 usuarios ${ }^{4}$. Como en el mundo real, el mapa de SL (que está formado por servidores conectados en todo el globo) se divide en $\operatorname{sims}^{5}$, espacios de terreno virtual. En estos terrenos, se producen los encuentros entre avatares y estos

\footnotetext{
${ }^{1}$ La versión beta aparece en 2002, aunque la versión definitiva se lanzó en junio de 2003.

${ }^{2}$ En SL también podemos encontrar juegos de rol: varios avatares usan un sim donde se desarrolla un juego en el que se adoptan otras personalidades.

${ }^{3}$ Prim: objeto primitivo, no basado en puntos de vector.

${ }_{5}^{4}$ Dato según Luis Sotillos en http://www.hoytecnologia.com/noticias/Second-Life-tiene-Espana/20571

5 "Este mundo virtual, su "terreno", está compuesto por SIMS que son espacios de unos $65.000 \mathrm{~m}^{2}$ virtuales, y que en la realidad corresponde a un procesador de un ordenador de un servidor. De ahí que dependiendo de la calidad de los servidores que soportan las sims, existan diferentes tipos de SIMS, clase 4, clase 5, etc. Según el tipo de servidor donde se encuentre, soportará más tráfico, prims o scripts sin tener lag (retardos espacio temporales)" ( http://secondlifedata.wordpress.com).
} 
encuentros pueden ser de todo tipo, pero hay algo común en todos ellos: para comunicarse, hay que utilizar el chat general o los mensajes privados, por escrito, y también se puede utilizar la voz. En realidad no se diferencia de cualquier programa de mensajería instantánea, pero con las ventajas visuales y estéticas de un mundo tridimensional, donde se pueden incrustar objetos que contengan audio, vídeo y herramientas colaborativas, es decir aplicaciones que faciliten que varios usuarios trabajen conjuntamente sin necesidad de que se encuentren reunidos en un mismo lugar físico. Con estas características, se podría decir que SL parece un lugar idóneo para la enseñanza.

En este artículo nos detendremos en la enseñanza del francés como lengua extranjera utilizando Second Life, analizando sus virtudes y sus desventajas. El trabajo que presentamos se fundamenta en la experiencia llevada a cabo con estudiantes de la Facultad de Ciencias del Turismo (URJC); los niveles abordados son A2 (francés general) y B1 (francés del Turismo).

Como ya hemos dicho, en SL el medio de comunicación es el chat, por lo tanto, sin que sea el objetivo específico de la plataforma, ya cumple con la interacción verbal escrita. Para comunicarse con otros avatares, hay que escribir, bien, mal, regular, con emoticones, abreviado, pero hay que escribir. Y los temas que se abordan son los mismos que se tocan en una conversación de carácter ordinario. Además, a medida que se va conociendo a otro avatar, a medida que se van desarrollando lazos con esa persona, los temas que se tratan van pasando de lo genérico a lo específico. Exactamente como en una relación social en RL (Real Life por oposición a second life. También se habla de "primera vida"). Y no vamos a abordar aquí si la persona que se esconde tras el avatar dice verdades o mentiras. No es mi objetivo estudiar el perfil sociológico del usuario ni su comportamiento. Lo que me interesa son las palabras, ya sean verdaderas o falsas.

¿Cuántos profesores de lengua materna habrían soñado con que sus estudiantes pasaran horas y horas teniendo una charla por escrito? Pues esto ya sucede desde hace años, con los chats, los mensajes instantáneos, etc. Si además el avatar desea practicar una lengua extranjera, tan solo tiene que desplazarse a algún sim donde haya un número elevado de usuarios de esa lengua e interactuar con ellos. Nada distinto de una situación verbal oral real: una persona viaja al extranjero, habla con los nativos y cuando desconoce el significado de alguna palabra, la pregunta o la busca en su diccionario de bolsillo (papel o electrónico). Y este avatar se comportará en SL del mismo modo que lo haría en RL: si es una persona segura, actuará con seguridad, afrontando los problemas y buscando soluciones, y si es una persona insegura, tardará más en relacionarse con los demás avatares y tal vez deje de intentarlo si la experiencia no ha sido positiva. La diferencia principal con la vida real es que el primer contacto se hará por escrito.

Ahora añadimos los sims dedicados a la enseñanza de lenguas extranjeras y observamos rápidamente que lo que se potencia es la comunicación oral, porque en SL también se puede usar la voz y, de hecho, se suele recurrir a ella cuando se está cansado, cuando se quiere dinamizar la charla. ¿Qué ha sucedido con los chats?, ¿por qué el avatar estudiante ya no quiere escribir y sí hablar? Las razones son 
sencillas. ¿Qué nos ofrecen estos sims? Hacer ejercicios camuflados bajo una forma atractiva de juego, ver vídeos, escuchar audios, es decir, ninguna novedad respecto de lo que se hace en cualquier clase dedicada a la enseñanza de una lengua extranjera en la que ya se hayan incorporado las TICs y además con un agravante: no se ve al profesor (sí, al avatar, pero éste no puede reflejar los gestos del profesor en tiempo real) y el estudiante necesita explicaciones y la manera más rápida de dar estas explicaciones es usando la voz. Aunque en realidad lo que el estudiante necesita siempre es un entorno dinámico:

Si se es principiante, el estudiante no quiere encontrarse con expositores de diseños con los que asocie imágenes con sus representaciones gráficas y auditivas;

Si se tiene un nivel intermedio, tampoco se desea hacer interminables ejercicios gramaticales;

Si se tiene un nivel avanzado, el estudiante tampoco desea leer novelas o redactar disertaciones.

Todo estudiante necesita tener la sensación de que progresa y esa progresión, en el aprendizaje de una lengua extranjera, pasa inevitablemente por la creencia de que se está sabiendo verbalizar, es decir, uno considera que está progresando cuando uno se siente capaz de participar en un intercambio verbal. Así pues todo lo visual que nos ofrece SL acaba resolviéndose de la manera "real": avatares usando la voz con otros avatares. De ahí que las numerosas instituciones de SL dedicadas a la enseñanza de una lengua extranjera fracasen ${ }^{6}$. Pero hay otros motivos. El usuario de SL suele utilizar el programa desde su casa. Puede estar cómodamente instalado en su hogar y no debe vencer la pereza de desplazarse físicamente para ir a una clase de lengua. Pero de igual modo que esto es una ventaja, también es una desventaja porque no está aislado de fenómenos que no pueden suceder en un aula: suena el teléfono, llaman a la puerta, hay otros miembros de la familia que requieren su atención, etc. El avatar/estudiante en realidad está frente a un ordenador que intenta recrear un aula, pero no está en un aula de estudio. Además puede verse interrumpido por la llegada de ims (instant messages) de sus contactos de SL. En realidad, se pretende ofrecer al estudiante autonomía, pero el usuario depende de su conexión a Internet y del huso horario de los demás avatares si quiere interactuar con ellos.

Si trasladamos SL a la clase de lengua, utilizando una modalidad de educación virtual basada en el blended learning, en la que se combinen los elementos propios

\footnotetext{
${ }^{6}$ Los alumnos que deciden continuar su actividad de aprendizaje de lenguas en SL suelen ser usuarios que han contratado los servicios de una academia con representación en el mundo virtual. Los grupos son reducidos (unos cinco estudiantes) y generalmente están formados por avatares que se conocen entre sí y deciden emprender esta actividad en común.
} 
del E-learning y la educación presencial, en una situación ideal en la que cada alumno disponga de un ordenador, el profesor puede disponer de un espacio en un sim donde reunirse con sus alumnos y utilizar SL como si de un documento audiovisual se tratara: visitar un terreno, observar el entorno, crear actividades y luego desarrollarlas en clase. Y esa explicación puede hacerse mediante el chat, escribiendo, y oralmente, en el aula. Además el profesor puede mandar actividades para otro día, de modo que el estudiante/avatar utilice SL por sí mismo, desde casa o desde cualquier otro lugar, y volver a reunirse con sus estudiantes en el espacio virtual y estando en el aula u organizar tutorías sin necesidad de que todos los miembros estén en clase. Y hasta aquí, SL es realmente un acierto.

El estudiante se siente motivado por un mundo nuevo que le ofrece increíbles posibilidades aún por explorar y en donde se siente amparado por la máscara que le proporciona el avatar. Es él, sí, pero de todos es sabido que el disfraz (Goffman, $1963,1967)$ ofrece al que lo lleva, ya sea en el mundo real o en el virtual, una libertad que le facilita un comportamiento que no suele tener. El estudiante se percibe distinto y esa percepción de su yo le lleva por lo tanto a poder manifestarse ante los demás de forma diferente. En este sentido, es muy interesante destacar la comunicación que el estudiante desarrolla con el profesor: incluso aunque aprendiente y docente estén compartiendo el mismo espacio físico, aunque los dos puedan verse en el aula, el estudiante se permitirá una libertad, dentro del mundo virtual, que jamás ejercería en una aula universitaria, a menos que estuviera interpretando un papel en un juego de roles realizado en clase.

SL se puede utilizar en todos los niveles de lengua. Utilizo el visor Imprudence ${ }^{7}$ y elijo que la interfaz del programa aparezca en francés. Todos los menús aparecen en esta lengua, por lo que los estudiantes se van familiarizando con los términos de las ventanas en el idioma en el que se imparte la asignatura. Si son estudiantes principiantes, se puede empezar por una clase centrada en la apariencia. El estudiante/avatar puede elegir su aspecto y la ropa que vestirá. Tenemos con ello todo el vocabulario sobre el cuerpo y la vestimenta: no solo me oirán decirlo en clase, sino que además lo leerán en el menú y las ventanas de diálogo. Esta actividad suele ser muy útil, puesto que a los estudiantes les divierte mucho modificar el físico de su avatar. Incluso les facilita poder interactuar con otros estudiantes con los que no suelen tener relación en el aula. Para rentabilizar los recursos, pueden crear "notas" en el programa y así ir creando un diccionario de uso personal con los términos que van apareciendo.

\footnotetext{
${ }^{7}$ http://wiki.kokuaviewer.org
} 

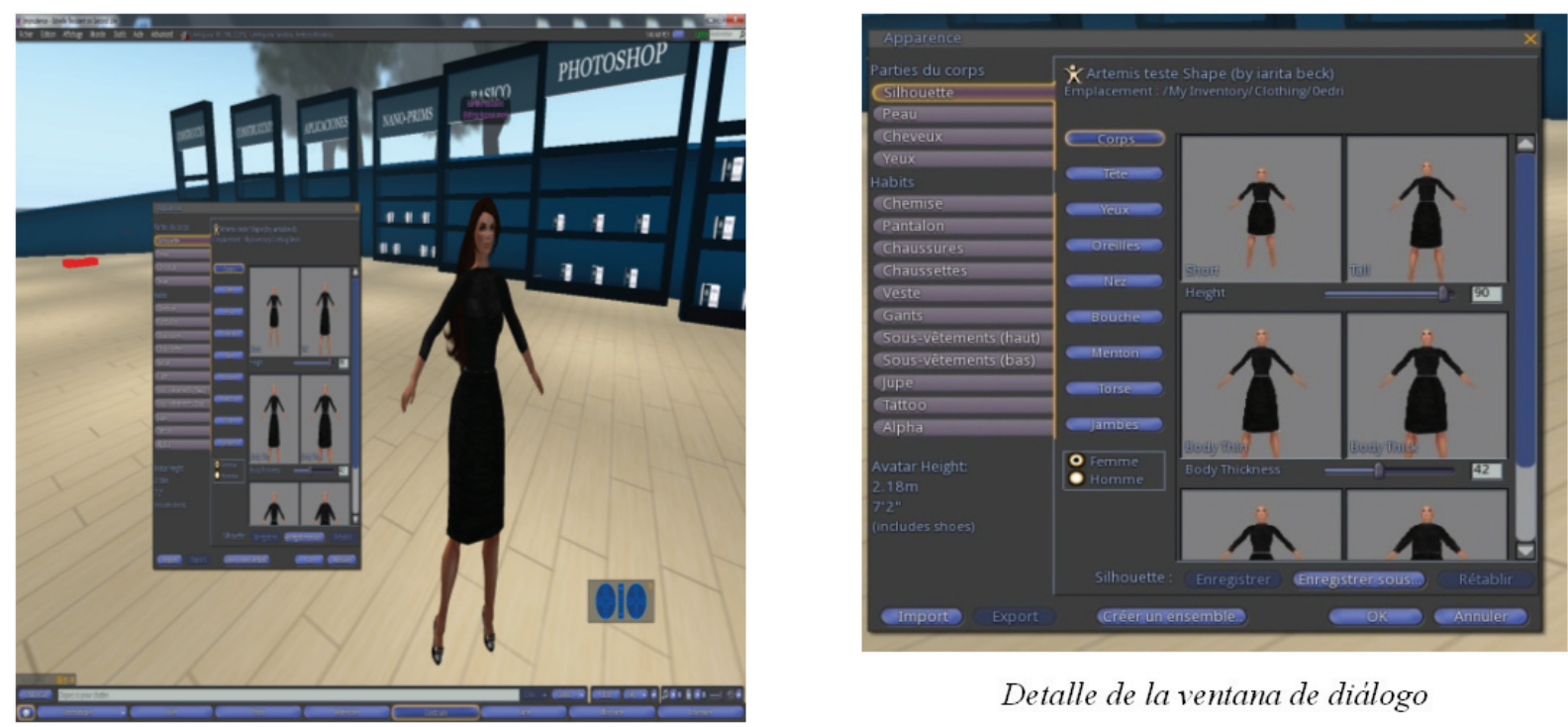

Detalle de la ventana de diálogo

Cuadro 1. Unhispana (http://slurl.com/secondlife/Unhispana/170/197/22)

También se puede dar una clase centrada en la construcción de objetos, la cual siempre resulta muy productiva puesto que el estudiante siente que interactúa con ellos y el mundo virtual en el que está:
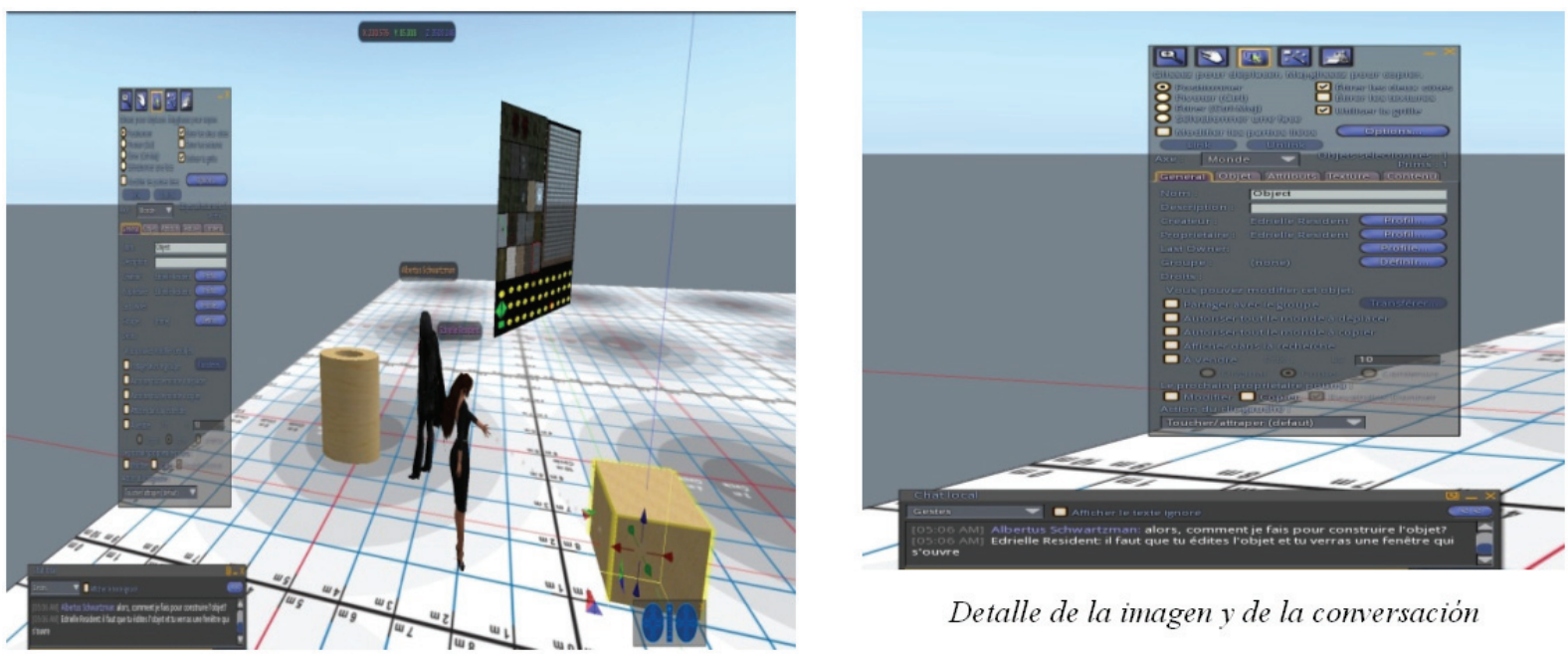

Detalle de la imagen y de la conversación

Cuadro 2. FRANCE3D Toulouse 
(http://slurl.com/secondlife/FRANCE3D\%20Toulouse/237/220/23)

Si la clase es de nivel intermedio o avanzado, puedo llevarlos a un sim que recree un entorno francés, como Arcachon o París, en los cuales todas las indicaciones y todos los objetos con los que interactúen ofrecerán la información en esta lengua, e indicarles que recreen situaciones de la vida diaria. Si están en una panadería, por ejemplo, un estudiante puede ser el vendedor y otros los compradores, interactuar con los objetos, escribir por el chat y luego guardar esa conversación y enviármela a través del campus virtual para que la corrija.
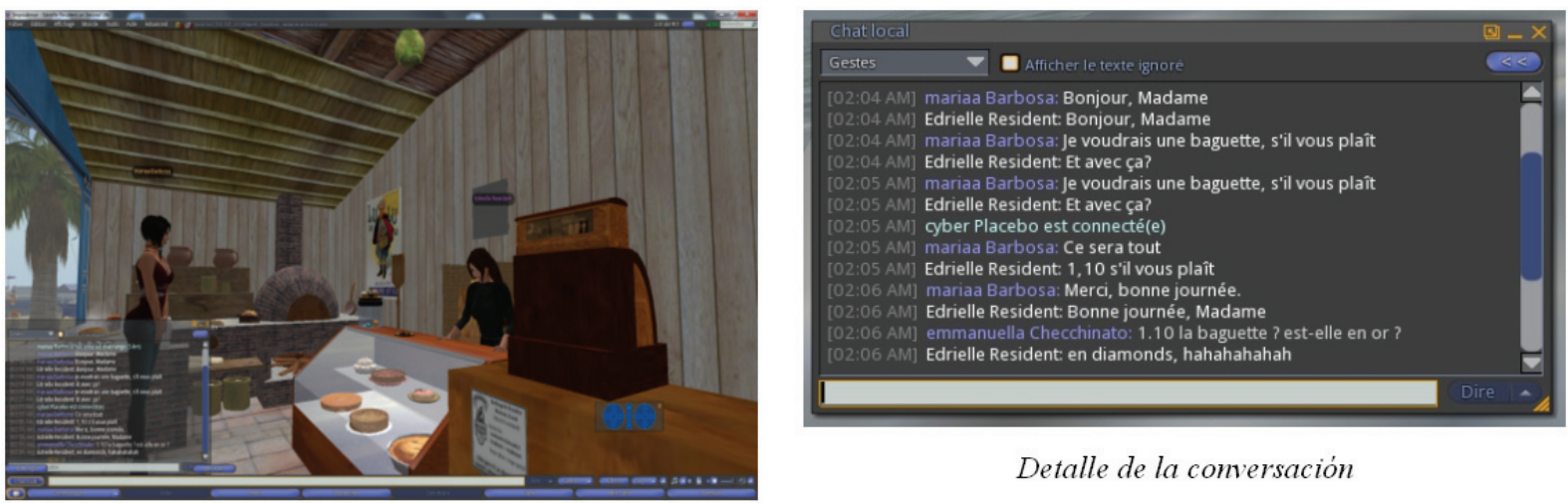

Detalle de la conversación

Cuadro 3. Arcachon (http://slurl.com/secondlife/Arcachon/200/212/25)

En una clase de nivel B1, se pueden tratar también temas específicos de la carrera que están estudiando los alumnos, en este caso, Turismo: 


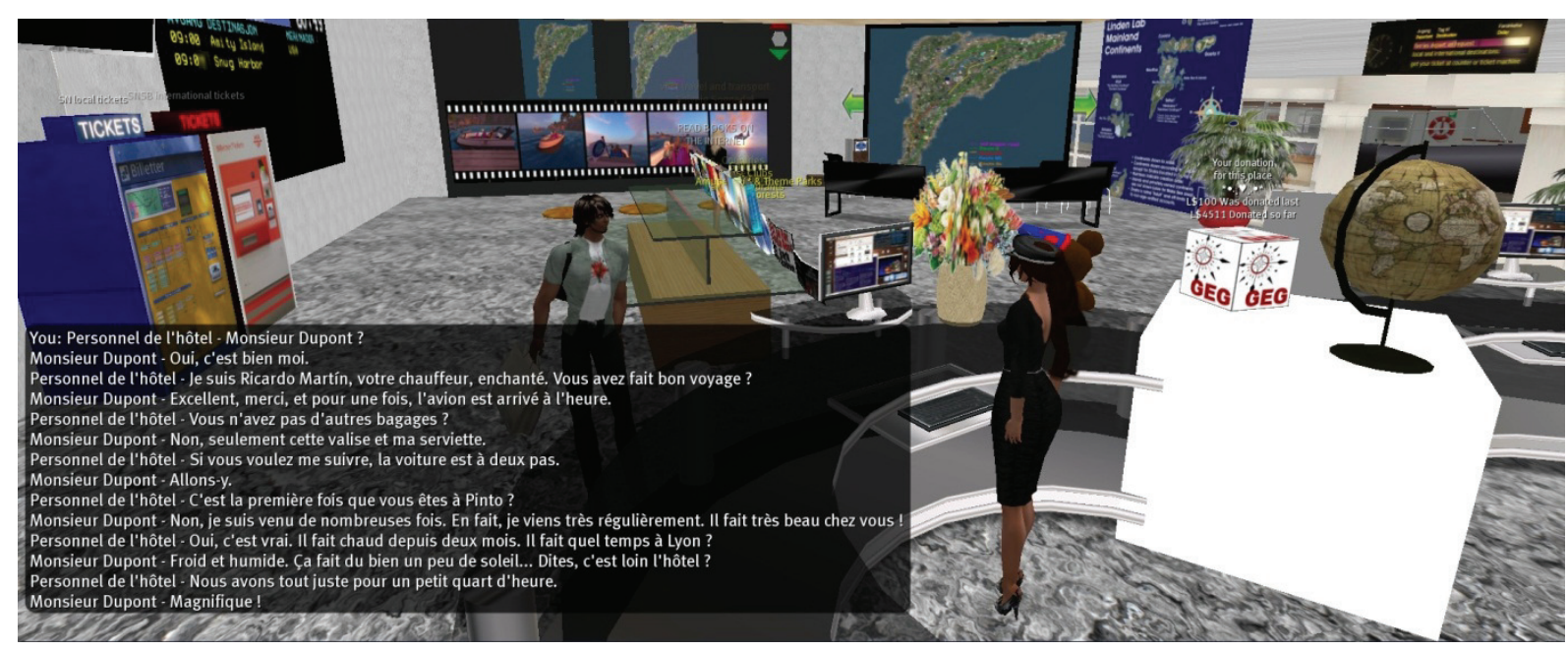

Cuadro 4. SLBA International Airport (http://slurl.com/secondlife/Thorkell/169/179/27)

Incluso si elijo un sim dedicado a la enseñanza del francés, los estudiantes podrán relacionarse con otros avatares nativos que, sin ningún problema, tendrán a bien hablar con ellos. Aunque esto puede ser un inconveniente, ya que si el sim no ha sido creado por usuarios europeos, nos encontraremos con el agravante del huso horario (SL se rige por el horario GMT -7), pero los estudiantes pueden encontrarse con otros avatares que estén visitando el sim en este momento, incluso con otros estudiantes extranjeros, con los que no sentirán ninguna vergüenza al escribir a través del chat, ya que se sentirán en la misma situación de aprendizaje. También encontrarán una serie de herramientas a su disposición que les indicarán cuáles son las direcciones donde se habla francés, qué páginas de FLE visitar en Internet, libros para descargar: 


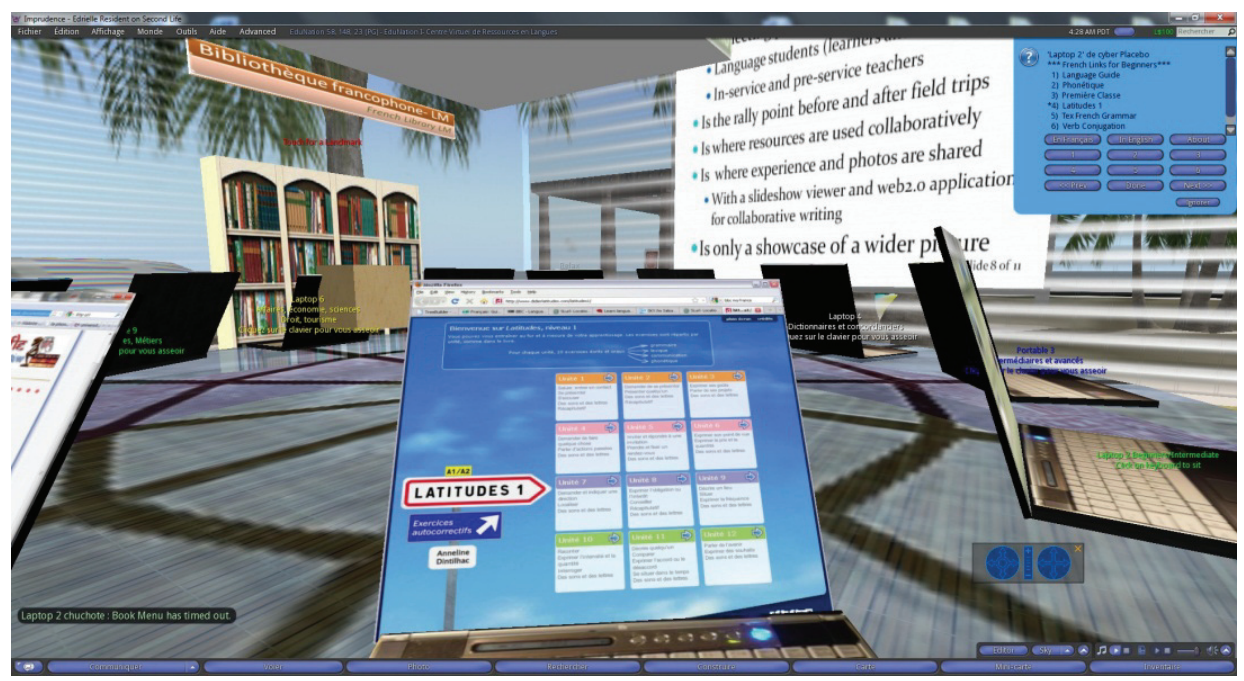

Cuadro 5. EduNation I - Centre Virtuel de Ressources en Langues (http://slurl.com/secondlife/edunation/56/139/23)

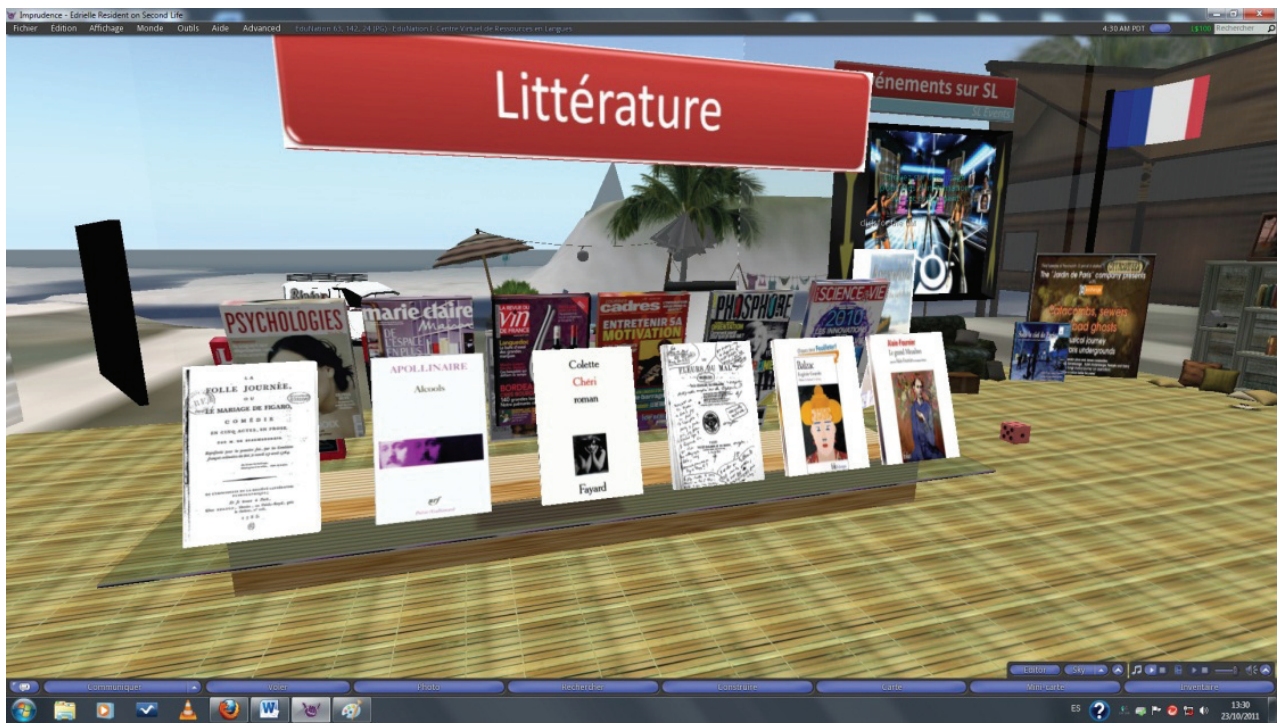

Cuadro 6. EduNation I - Centre Virtuel de Ressources en Langues (http://slurl.com/secondlife/edunation/56/139/23) 
El enfoque pedagógico es claramente constructivista (Williams \& Burden: 1999) - comunicativo (Brumfit \& Johnson: 1971) y lo que se potencia es la relación alumno-alumno, a través del chat. Y no debemos olvidar que el chat no es tan solo un texto escrito, es la representación escrita de una verbalización. Es el primer paso hacia la comunicación oral. Si el estudiante sabe que se está expresando con otro estudiante, aunque sea por escrito, no tendrá el miedo habitual a la presión de hacerlo oral y públicamente en el aula. Y además no le importará cometer fallos, sino que lo que estará intentando ante todo es hacerse entender. Por eso es importante que, en esta fase, el profesor no devuelva chats corregidos de la manera habitual, teniendo en cuenta la ortografía, el uso del léxico y la gramática, sino que entregue esas conversaciones con comentarios que estimulen las producciones posteriores. Además esta toma de contacto del estudiante con otro miembro de la comunidad de SL puede prolongarse en el tiempo y con voz una vez que el estudiante haya terminado las clases y esta independencia es claramente motivadora, ya que se entiende el espacio del aula como el lugar en el que se produce el primer encuentro para un posterior conocimiento, independiente de la presencia del profesor.

Y hay algo que el enseñante no debe olvidar. Sus alumnos son nativos digitales ${ }^{8}$ :

Estos nativos digitales normalmente tienen ganas de aprender de una manera más social. Quieren que las actividades de aprendizaje sean más interactivas y basadas en tareas reales y cotidianas. Además, buscan la comunicación inmediata, lo que las comunidades en línea ofrecen (Vickers: 2007a).

Pero ¿supone esta interacción realmente una novedad? Ya en la web de la plataforma Galanet ${ }^{9}$ leemos:

Esta plataforma, realizada en el marco de un proyecto europeo Socrates Lingua (2001-2004) permite a hablantes de distintas lenguas románicas la práctica de la intercomprensión, es decir, un tipo de comunicación plurilingüe en la que cada participante comprende las lenguas de los demás y se expresa en la o las lengua(s) románica(s) que conoce, desarrollando diferentes niveles de conocimiento de estas lenguas. La elaboración de un proyecto común motiva la comunicación, fomentada por la labor de los tutores y la variedad de recursos disponibles.

Este dispositivo, que se basa en la disociación temporal de las destrezas y en las propiedades de la formación híbrida, está destinado a estudiantes de enseñanza superior, de centros de lenguas, de secundaria o a cualquier adulto que domine al menos una lengua románica de referencia, como lengua materna o extranjera y que no sea necesariamente principiante en las otras lenguas.

Un proyecto iniciado en 2001 en el que se promovía la intercomprensión e interacción entre estudiantes a través de los chats, los foros y el correo electrónico y que

\footnotetext{
${ }^{8}$ Término acuñado por Mark Prensky en 2001.

${ }^{9} \mathrm{http}: / /$ www.galanet.be
} 
actualmente ha dado lugar a Galapro ${ }^{10}$, la plataforma para la formación de formadores en la intercomprensión en lenguas románicas.

Podemos decir entonces que la verdadera novedad que supone SL viene dada por la tridimensionalidad del mundo que nos ofrece y por la presencia visual de un avatar que representa al estudiante y al profesor. Una innovación brillante, que revoluciona el concepto de la percepción espaciotemporal, que facilita la comunicación sincrónica, que permite la visita virtual de copias de la realidad y que promueve la creatividad. Y como ya señalamos anteriormente, la posibilidad de ocultarse tras un disfraz liberador que hace que la experiencia de hablar en una lengua que no se domina no sea tan angustiosa ${ }^{11}$.

Pero ¿durante cuánto tiempo se puede utilizar SL en una clase? Mi experiencia me ha demostrado que es un recurso que puede agotarse fácilmente (si el profesor no ha preparado concienzudamente las actividades) porque, tras la primera sorpresa que supone el uso de la plataforma en el aula, al estudiante le asalta la duda sobre cómo será evaluado. Y este dato me parece revelador: el estudiante está aprendiendo con SL, interactúa con otros avatares sin temor, siente curiosidad por las posibilidades del mundo virtual, pero no lo percibe como una forma seria de estudio. Henao (2002: 81) lo especificaba claramente:

Un buen curso virtual no se diseña colocando literalmente en la red el programa y los contenidos de una clase tradicional. Se trata de una tarea más compleja, que exige a los docentes aprender nuevas habilidades tecnológicas, otras formas de organizar contenidos, e incluso un nuevo estilo de enseñanza.

Un nuevo estilo de enseñanza, sí, pero también un nuevo estilo de aprendizaje, en el cual las nuevas tecnologías no solo sean percibidas como fuentes de información y de entretenimiento, sino como auténticas fuentes al servicio del conocimiento. "Aprender a enseñar" y "aprender a aprender". Las estrategias de aprendizaje cognitivas y metacognitivas deben ser reestudiadas de modo que tanto estudiante como profesor entiendan que:

Ello facilita la modificabilidad estructural cognitiva y afectiva desde el siguiente supuesto: los contenidos (formas de saber) y los métodos (formas de hacer) son medios para desarrollar capacidades (a partir de destrezas y habilidades) y valores (a partir de actitudes) (Román: 2005:10).

\footnotetext{
${ }^{10} \mathrm{http}: / /$ www.galapro.eu

${ }^{11}$ El alumno sabe que en cualquier momento puede dejar la comunicación, si no se siente a gusto, tan solo con cerrar el programa. El que decide seguir adelante señala que lo que pierde con ese disfraz es el lenguaje no verbal de su interlocutor, aunque suele resolverlo añadiendo emoticones al chat. En el caso de estar utilizando el micrófono, se encuentra ante el mismo problema que podría resultar de tener que realizar una llamada en una lengua extranjera. El paso a la voz suele llevar un tiempo, incluso en SL.
} 
De ahí que, para que el uso de SL en el aula sea fructífero, el docente tenga que insistir en la situación, el evento y no en el entorno, es decir, a la novedad del mundo virtual hay que conferirle la seriedad de una enseñanza comprobada en la cual el estudiante considere que es una herramienta didáctica válida. Esta "seriedad" conlleva una ardua labor por parte del docente, y como usuaria de SL en el aula, la explicaré a través de mi experiencia:

- En primer lugar, he podido enseñar con SL cuando el número de alumnos matriculados en la asignatura de Francés no superaba los 25 , ya que esta es la capacidad del aula de ordenadores, por lo tanto, estas prácticas las he realizado con los estudiantes del turno de tarde, puesto que por las mañanas, mis clases rondan los 70 estudiantes. No he potenciado el uso de ordenadores portátiles debido a que en estos la memoria de las tarjetas gráficas es a veces compartida y reduce las posibilidades de mayor velocidad recortando la memoria ram convencional. El sobrecalentamiento de los portátiles también es un aspecto a tener en cuenta y la especificidad de algunos fabricantes en la gestión de los drivers de dispositivo de notebooks puede imposibilitar el funcionamiento del visor.

- He considerado que 25 estudiantes es el número máximo para que en este tipo de docencia y en una hora y media, que es la duración de la clase, pueda atender a todos los estudiantes sin que la clase se convierta en una lección magistral sobre el uso de SL.

- En segundo lugar, las actividades para realizar en clase, con SL, han supuesto días de elaboración, análisis e investigación: buscar un sim adecuado, donde se pudiera construir y abrir objetos (sandboxes gratuitos) ${ }^{12}$, para iniciar a los estudiantes en el uso de las posibilidades de SL; localizar sims francófonos con categoría "Público general" "13 en los que mis estudiantes pudieran participar en intercambios comunicativos con otros avatares; contactar con otras instituciones españolas y francófonas que también usaran SL en sus clases de lengua extranjera y quisieran realizar actividades conjuntas; crear eventos didácticos que permitieran que el estudiante sintiera que formaba parte de una comunidad y, lo más importante, contextualizar el aprendizaje, articulándolo con aspectos de la realidad para que el estudiante sintiera en todo momento que podría reutilizar ese conocimiento más adelante.

- En tercer y último lugar, si me he decidido a usar SL en las clases de francés es porque previamente había tenido experiencia como usuaria de esta plataforma,

\footnotetext{
${ }^{12}$ En SL, el terreno no es gratuito. Si se desea poseer una parcela, el precio vendrá dado por el número de metros cuadrados de extensión virtual y por el número de prims que se puede colocar. El sandbox es una parcela de terreno abierta al público en general donde se puede construir y usar scripts.

${ }^{13}$ Los sims están clasificados en función de sus contenidos: General public, mature y adult. En los sims "adult", el contenido sexual es muy alto.
} 
y lo que he hecho es volcar mis conocimientos y experiencias de SL en una aplicación didáctica en la que he motivado las conexiones de la inmediatez de Internet con los conocimientos tradicionales comunicativos.

La experiencia ha sido sin duda alguna muy enriquecedora tanto para los estudiantes como para mí, pero me gustaría finalizar insistiendo en que el uso de SL en la enseñanza de una lengua extranjera requiere innumerables esfuerzos por parte del docente. No se trata de usar SL, se trata de rentabilizar este recurso de manera que pueda ser reutilizable. SL no es un fin, es un medio más y como tal requiere un conocimiento profundo y unas capacidades organizativas que refuercen la situación y el contexto para que el estudiante asimile que está aprendiendo.

\section{REFERENCIAS BIBLIOGRÁFICAS}

Brumfit, C. \& K. Johnson, (1971) The Communicative Approach to Language Teaching. Oxford, Oxford University Press.

Gaspar Verdú, V., (2005) "Utilidad de las nuevas tecnologías en lengua alemana para universitarios. Experiencias didácticas desde un enfoque constructivista" en mAGAzin [En línea]. $\mathrm{N}^{\mathrm{o}} 16$, disponible en: http//:www.fage.es/magazin/magazin 16/mag16_02_gaspar.pdf

Goffman, E., (1963) Behaviour in Public Places. Nueva York, The Free Press.

- (1967) Interaction Ritual-Essays on Face-to Face Behaviour. Nueva York, Anchor Books.

Henao Álvarez, O., (2002) La enseñanza virtual en la educación superior [En línea]. Bogotá, ICFES, disponible en: http//:www.pucmm.edu.do/RSTA/Academico/ TE/Documents/ed/eves.pdf

Molka-Danielsen, J. \& M. Deutschsmann, (2009) Learning and Teaching in the Virtual World of Second Life. Trondheim, Tapir Academic Press.

Muvenation, (2010) European Project: Collection of Educational Tools for Second Life and Pedagogical Practices for Virtual Worlds [En línea]. Disponible en: http://muvenation.org

Prensky, M., (2001) "Digital Natives, Digital Immigrants" in On the Horizon [En línea]. Vol. $9, \mathrm{n}^{\circ} .5$, disponible en línea en: http://www.marcprensky.com

Román Pérez, M., (2005) Aprender a aprender en la sociedad del conocimiento. Santiago de Chile, Conocimiento S.A.

Salmon, G., (2004) E-moderating: the Key to Teaching and Learning Online. London, Taylor and Francis.

Siemens, G., (2004) Conectivismo: Una teoría de aprendizaje para la era digital [En línea]. Disponible en: http://es.scribd.com/doc/201419/Conectivismo-unateoria-del-aprendizaje-para-la-era-digital [Último acceso el 26 de marzo de 2012] Vickers, H., (2007a) Language teaching gains second life [En línea]. Omniglot: Writing Systems and Languages of the World Web site, disponible en: http://www.omniglot.com/language/articles/secondlife.php 
Vickers, H., (2007b) Las aventuras SurRealistas: el aprendizaje de idioma enriquecido y decidido en Second Life [En línea]. The knowledge tree, disponible en: http://kt.flexiblelearning.net.au/tkt2007 [Último acceso del 26 de marzo de 2012]

Williams, M. \& R. Burden, (1999) Psicología para profesores de idiomas. Cambridge, Cambridge University Press. 